\title{
Prevalence of coexistence genes and clonal spread of ESBL-producing isolates causing hospital- and community-acquired infections in Zenica-Doboj Canton, Bosnia and Herzegovina
}

\author{
Amir Ibrahimagić1* , Selma Uzunović ${ }^{1}$, Branka Bedenić2,3 \\ 'Department for Laboratory Diagnostics, Institute for Public Health and Food Safety, Zenica, Bosnia and Herzegovina, \\ ${ }^{2}$ Department of Medical Microbiology and Parasitology, School of Medicine, University of Zagreb, Zagreb, Croatia, \\ ${ }^{3}$ Department for Clinical and Molecular Microbiology, Clinical Hospital Center Zagreb, Zagreb, Croatia
}

\begin{abstract}
Introduction: Coexistence type of extended-spectrum beta-lactamases (ESBL)-producing isolates is serious problem in the public health world.
\end{abstract}

Materials and Methods: Antibiotic susceptibility was determined by disc diffusion and broth microdilution according to the Clinical and Laboratory Standards Institute guidelines. Double-disk synergy test was performed to screen for ESBLs/pAmpC beta-lactamases. Polymerase chain reaction (PCR) was used to detect bla $\mathrm{ESBL}_{1} / \mathrm{bla}_{\mathrm{ampc}} \mathrm{C}^{\prime}$ bla $a_{\text {carb }}$ genes. Genetic relatedness of the strains was determined by pulsed-field gel electrophoresis.

Results: In this study, 88 of the inpatient isolates $(n=126 ; 10.0 \%)$ and 62 of the outpatient $(n=184 ; 6.4 \%)$ beta-lactamase-producing isolates were taken for the study. They included 50.0/29.0\% Klebsiella pneumoniae, 12.5/30.6\% Escherichia coli, 11.4/4.8\% Acinetobacter baumannii, 8.0/14.5\% Klebsiella oxytoca, 8.0/4.8\% Enterobacter cloacae, $5.7 / 8.1 \%$ Proteus spp., and $<3.5 \%$ of other isolates. Coexistence of more than two types of beta-lactamases was detected in $77.3 \%$ of inpatient and $45.2 \%$ of outpatient isolates. Among inpatient isolates, Klebsiella spp. and $E$. coli were the most frequent isolates which produce more than two types of genes, in $\approx 65 \%$ and $\approx 12 \%$ of cases. Separately, combination of four TEM+SHV+CTX-M+OXA-1 beta-lactamases in inpatient $K$. pneumoniae isolates was detected in $63.6 \%$ of cases, respectively. Differences in antimicrobial resistance were higher to cephalosporin agents in Klebsiella spp. and E. coli at inpatient and outpatient isolates which produce more than two types of beta-lactamases than in isolates which produce one type of beta-lactamases.

Conclusion: This work demonstrates a progressively increasing prevalence of coexistence type of beta-lactamases, especially in inpatient isolates. Continuous monitoring and surveillance and proper infection control and prevention practice will limit the further spread of these isolates.

Key words: Coexistence type of extended-spectrum beta-lactamases; comparison; antimicrobial resistance

\footnotetext{
*Corresponding author: Amir Ibrahimagić, Institute for Public Health and Food Safety Zenica Fra Ivana Jukića 2, 72000 Zenica, Bosnia and Herzegovina. Tel.: 0038732/443-580. Fax.: 0038732/443-530. E-mail: ibrahimagic.amir@gmail.com
} 


\section{INTRODUCTION}

Most of the genes encoding extended-spectrum beta-lactamases (ESBLs) are generally found on plasmids that conferred resistance to multiple antibiotic classes and are readily transferable between and within bacterial pathogens (1). Family of cefotaxime beta-lactamases (CTX), after SHV-1 and TEM-1 has been reported with increasing frequency in the world (2). These genes are commonly found with other resistance genes, causing a coresistance profile inclusive of other non-beta-lactam antibiotics such as aminoglycosides and tetracycline (3).

In recent years, the production of more than one beta-lactamase has frequently been reported in some countries, such as in the study from India (4,5), China (6), Iran (7), and Germany (8), Egypt (9), USA (10), Malaysia (11), and Bosnia and Herzegovina (B and $\mathrm{H})$ (12). The antimicrobial resistance of Gram-negative bacteria has risen progressively during the past decades, leading to an increasing number of outbreaks due to the existence of multi-resistant bacteria, especially those producing more than one beta-lactamase type (4). Escherichia coli and Klebsiella pneumoniae are major agents and also the most frequent bacteria that produce different type of ESBLs. Now, it is a serious problem in the world, because the emergence of multiple-ESBLs is the important cause of transferable multidrug resistance in Gram-negative bacteria (13).

In the study from Zenica-Doboj Canton (B and $\mathrm{H}$ ) (2015), the coexistence of several ESBL types in the same bacterial strain causing inpatient and outpatient urinary tract infections was found with prevalence rates of $44.4 \% / 50 \%$ in E. coli, $81.8 \% / 30 \%$ in K. pneumoniae, and $66.7 \% / 22.2 \%$ in Klebsiella oxytoca, respectively (12).

The aim of the study was to investigate a prevalence, antimicrobial characteristics, and mode of spread of Gram-negative isolates producing more than two different beta-lactamase types causing in- and out-patient infections in Zenica-Doboj Canton, B and $\mathrm{H}$.

\section{MATERIALS AND METHODS}

\section{Setting, bacterial isolates, and study design}

All consecutive, non-duplicate Gram-negative isolates collected from different specimens and resistant to expanded-spectrum cephalosporins from various hospital departments, including outpatient department, of the Cantonal Hospital Zenica, B and $\mathrm{H}$, in the period December 2009 - May 2010 were included in the study. The Cantonal Hospital Zenica is 849-bed tertiary level hospital admitting about 25,000 patients/ year, with 2,40,000 hospital days, and covers a population of 3,31,229 in Zenica-Doboj Canton.

The Institutional Review Board approval from the Ethics Committee of the Cantonal Hospital Zenica was obtained before the initiation of the study.

\section{Detection of ESBLs, plasmid-mediated AmpC $\beta$-lactamases, and carbapenemases}

A double-disk synergy test using the combination of amoxicillin/clavulanate with cefotaxime, ceftriaxone, ceftazidime, and cefepime was performed to detect the production of ESBLs (14). Production of ESBLs was confirmed according to the Clinical and Laboratory Standards Institute (CLSI) combined disk test.

E. coli, Klebsiella spp., Enterobacter spp., Citrobacter spp., Morganella morganii, and Proteus spp. strains resistant to expanded-spectrum cephalosporins, cefoxitin, and beta-lactam combinations with inhibitors were screened for the production of AmpC beta-lactamase. Production of AmpC beta-lactamase was tested by combined disk test using 3-amino phenylboronic acid (PBA) (15).

Production of carbapenemases Group A or Group B was confirmed by combined disk test using EDTA and PBA (16).

\section{Susceptibility testing}

Susceptibility testing to 12 antimicrobials was performed by a two-fold microdilution technique according to the CLSI standard procedure: Amoxycillin+clavulanic acid (AMC; 20+10 $\mu \mathrm{g}$ ), cefazolin (CZ; $30 \mu \mathrm{g})$, cefuroxime (CXM; $30 \mu \mathrm{g})$, ceftazidime (CAZ; $30 \mu \mathrm{g}$ ), cefotaxime (CTX; $30 \mu \mathrm{g}$ ), ceftriaxone (CRO; $30 \mu \mathrm{g}$ ), cefoxitin (FOX; $30 \mu \mathrm{g}$ ), cefepime (FEP; $30 \mu \mathrm{g}$ ), imipenem (IMP; $10 \mu \mathrm{g})$, meropenem (MEM; $10 \mu \mathrm{g})$, gentamicin (GM; $10 \mu \mathrm{g}$ ), and ciprofloxacin (CIP; $5 \mu \mathrm{g}$ ) (14). E. coli ATCC 25922 (ESBL negative) and $K$. pneumoniae 700603 (ESBL positive) were used as quality control strains. 
Polymerase chain reaction (PCR) detection of $b / a_{\mathrm{CTX}-\mathrm{M}}, b / a_{\mathrm{SHV}}, b / a_{\mathrm{TEM}}$, and $b / a_{\mathrm{KPC}}$ genes

PCR was used to detect alleles encoding ESBL enzymes.

The presence of $b l a_{\mathrm{TEM}}, b l a_{\mathrm{SHV}}$ and $b l a_{\mathrm{CTX}-\mathrm{M}}$ genes was investigated by PCR using primers and conditions as described previously (17).

Primers IS26F (5'-GCG-GTA-AAT-CGT-GGAGTG-AT-3) and IS26R (5'-ATT-CGG-CAA-GTTTTT-GCT-GT-3') were used to amplify $400 \mathrm{bp}$ fragment spanning the link between IS26 insertion sequence and bla ${ }_{\text {Стх-м }}$ gene in CTX-M-producing isolate (18). Genes encoding carbapenemases of Group A (KPC), Group B (MBLs belonging to VIM, IMP, and NDM family), and OXA-48 were detected by PCR as described previously (16).

\section{Molecular detection of plasmid-mediated AmpC $\beta$-lactamases}

Multiplex PCR with primers specific for MOX, CMY, DHA, ACT, MIR, and FOX $\beta$ lactamases was used to detect plasmid-mediated Amp $\beta$-lactamases in strains resistant to cefoxitin and $\beta$-lactam/inhibitor combinations (15).

\section{Typing by pulsed-field gel electrophoresis (PFGE) of bacterial DNA}

Isolation of genomic DNA, digestion with the $X b a \mathrm{I}$ restriction enzyme (Invitrogen), and PFGE of the resulting fragments were performed as described by Kaufman (19). The electrophoresis was carried out with a CHEF-DRII apparatus (Bio-Rad Laboratories, Hercules, CA). The PFGE patterns were compared following the criteria of Tenover et al. (20) and analyzed by the GelComparII software (Applied Maths, St Martens, Belgium).

\section{RESULTS}

\section{ESBL prevalence}

During the period December 2009-May 2010, a total number of 1254 consecutive, non-duplicate inpatient, and 2857 outpatient Gram-negative bacteria were isolated. Among inpatient samples, $126(10.0 \%)$ were beta-lactamase-producing isolates, $40(31.7 \%)$ were from urine samples, 35 (27.8\%) from surgical wounds, 15 (11.9\%) from skin and soft tissue infections (SSTIs), 14 (11.1\%) from cannula and stoma, 13 (10.3\%) from upper respiratory tract, $5(4.0 \%)$ from burns, and $4(3 \%)$ from other samples (catheters and ear swabs).

Among outpatient samples, 184 (6.4\%) were beta-lactamase-producing isolates, of which $148(80.4 \%)$ were from urines, 30 (16.3\%) from surgical wounds, and $6(3.3 \%)$ from other samples (SSTIs, upper respiratory tract, ear swabs, genital tract, and eyes).

A total of 88 inpatient and 62 outpatient isolates were available for further analysis including $44 / 18(50.0 / 29.0 \%) \quad K$. pneumoniae, $11 / 19$ (12.5/30.6\%) E. coli, 10/3 (11.4/4.8\%) Acinetobacter baumannii, 7/9 (8.0/14.5\%) K. oxytoca, 7/3 (8.0/4.8\%) E. cloaceae, 5/5 (5.7/8.1\%) Proteus spp., and 4/5 (3.5\%) of other in/outpatient isolates (C. freundii, M. morganii, and $P$. aeruginosa).

Most of the 88 ESBL-producing inpatient strains originated from the pediatric and neurology departments, $29(33.0 \%)$ and $18(20.5 \%)$ isolates.

The most common beta-lactamase-producing inpatient isolates were $K$. pneumoniae 44 (50.0\%), and E. coli 11 (12.5\%), followed by ten A. baumannii, seven $K$. oxytoca, seven Enterobacter cloacae, five Proteus spp., three $C$. freundii, and one $P$. aeruginosa $(11.4 \%, 8.0 \%, 8.0 \%, 5.7 \%, 3.4 \%$, and $1.1 \%$, respectively). The most common beta-lactamase-producing outpatient isolates were $E$. coli 19 (30.6\%) and K. pneumoniae 18 (29.0\%), followed by nine $K$. oxytoca, five Proteus spp., three E. cloacae, three $A$. baumannii, two $C$. freundii, two M. morgannii, and one $P$. aeruginosa $(14.5 \%, 8.1 \%$, $4.8 \%, 4.8 \%, 3.2 \%, 3.2 \%$, and $1.6 \%$, respectively).

Thirty-six (of 88, 40.9\%) isolates were obtained from the inpatients older than 60 years of age, followed by the group below 1 year of age, 25 (28.4\%). Duration of hospitalization (median) was 14 days; in seven cases, duration of hospitalization was in the range 33-54 days. Amoxicillin-clavulanic, gentamicin, and cefazolin were mostly used antimicrobials in the inpatient infections caused by beta-lactamase-producing isolates, in 39, 23, and 22 (44.4\%, $26.4 \%$, and $25.0 \%$ ) cases, respectively.

Twenty-seven (of 62, 43.5\%) beta-lactamase-producing isolates were obtained from the outpatients older than 60 years of age, followed by children 
up to 1 year of age, $16(25.8 \%)$. Other data for outpatients were missing.

\section{Detection and characterization of $\beta$-lactamases}

Among the 88 and 62 beta-lactamase-producing in- and out-patient isolates, 61 (69.3\%) and 19 (30.6\%), respectively, were positive for $b a_{\text {СTX-M }}$ gene by PCR.

Sixty-eight (77.3\%) inpatient and 29 (46.8\%) outpatient isolates coproduced more than two genes in different combinations: $b l a_{\mathrm{CTX}-\mathrm{M}}, b l a_{\mathrm{TEM}-1}, b l a_{\mathrm{SHV}-1}$, $b l a_{\text {OXA-1 }}, b l a_{\text {DHA-1 }}$, or $b l a_{\text {CMY-2 }}$.

Forty-five (of 51, 88.2\%) inpatient beta-lactamase-producing Klebsiella spp. $(38 \mathrm{~K}$. pneumoniae and $7 \mathrm{~K}$. oxytoca) coproduced more than two types of different genes including $b l a_{\mathrm{CTX}-\mathrm{M}}, b l a_{\mathrm{TEM}}, b l a_{\mathrm{SHV}}, b l a_{\mathrm{OXA}-1}$, $b l a_{\mathrm{CMY}-2}$, or bla $a_{\mathrm{DHA}-1}$ (Tables 1 and 2).

Ten (of 19, 52.6\%) outpatient beta-lactamase-producing E. coli isolates coproduced more than two types of beta-lactamases (Tables 1 and 2).

\section{Characterization of carbapenemases}

Carbapenemases were not detected neither by phenotypic nor molecular tests.

\section{Antibiotic susceptibility}

\section{Isolates with one type of beta-lactamases}

Prevalence of resistance to all cephalosporin antibiotics was noticed among six inpatient Klebsiella spp., six A. baumanni, and seven other isolates (one Citrobacter freundii, two $E$. coli, three E. cloacae, and one Pseudomonas spp.) ranging from $14.3 \%$ to $100 \%$. Gentamicin and ciprofloxacin also showed the low activity, 42.9-83.3\%, respectively. Resistance to imipenem and meropenem in A. baumanni was noticed in $83.3 \%$ and $16.7 \%$.

Nine E. coli and 12 Klebsiella spp. outpatient isolates were resistant to cephalosporins, aminoglycosides, and fluoroquinolones, with the resistance rates ranging from $25.0 \%$ to $100.0 \%$.

One $A$. baumannii isolate was resistant to imipenem and meropenem (Table 3).

\section{Isolates with more than two types of beta-lactamases}

ESBL-producing E. coli and Klebsiella spp. inpatient isolates which produced two and more than two types of beta-lactamases had higher resistance rates to ceftazidime, cefotaxime, and ceftriaxone with the range of $50-90 \%$, than in isolates which produced one or two types of beta-lactamases. The same isolates were resistant to gentamicin and ciprofloxacin (Table 3).

In outpatient, ESBL-producing E. coli and Klebsiella spp. isolates, coproducing more than two types of beta-lactamases, had higher resistance rates to ceftazidime and ceftriaxone than isolates with one type of beta-lactamases (Table 3).

\section{PFGE typing}

The genetic relatedness was examined through PFGE typing. Forty-one isolates of $K$. pneumoniae, 18 of E. coli, 11 of Proteus spp., 10 of E. cloacae, and six of $C$. freundii isolates were available for the analysis (Figure 1).

\section{DISCUSSION}

In the present study, a high prevalence of ESBLproducing isolates which produced two and more than two types of beta-lactamases and their antimicrobial resistance patterns have been reported for the first time in the Zenica-Doboj Canton, B and $\mathrm{H}$.

CTX-M was the most prevalent gene in inpatient ESBL-producing isolates in this study (70\%), as it was also reported in some other countries where the prevalence was $96.9 \%$ in China (5), 80.3\% and $91.3 \%$ in Germany $(8,21)$, and $75.5 \%$ in Madagascar (22). In outpatients, TEM was the most prevalent gene $(50 \%)$.

The presence of more than two different types of beta-lactamases in the same isolates in this study was noticed, $77 \%$ in inpatient, and $47 \%$ in outpatient. This is similar with the report from India, Germany, Malaysia, and Iran where the prevalence of coproduction of more than two types of beta-lactamases in inpatient was $70 \%, 77 \%, 50 \%$, and $45 \%(5,8,11,13)$, respectively. These prevalences are lower in the report from China (11\%), North Iran $(30 \%)$, and Egypt $(10 \%)(6,7,9)$.

Coproduction of more than two types of beta-lactamases was most frequently noticed in Klebsiella spp. (66\%), which is in concordance with the report from India (70\%) (5). This result is not in agreement 


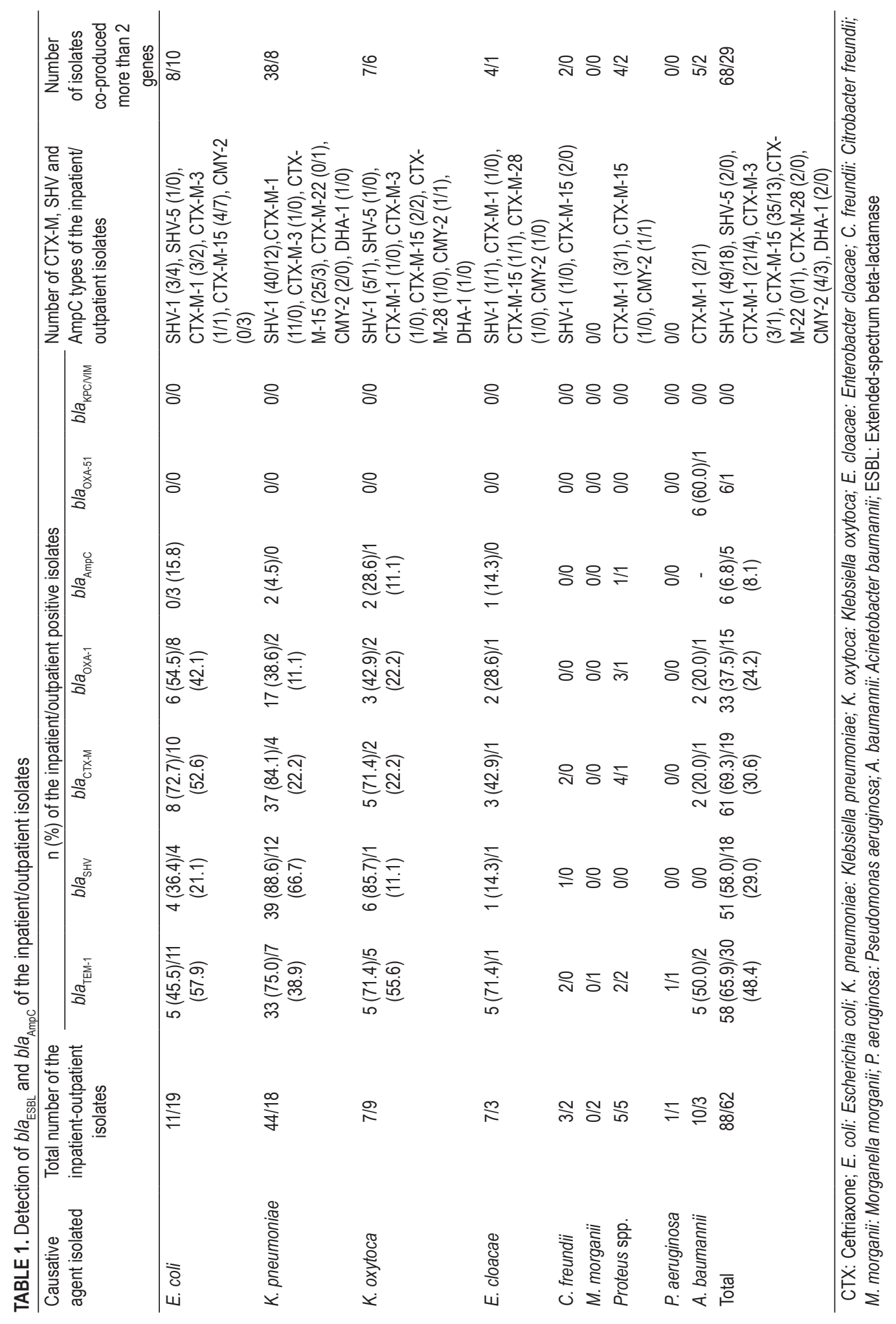




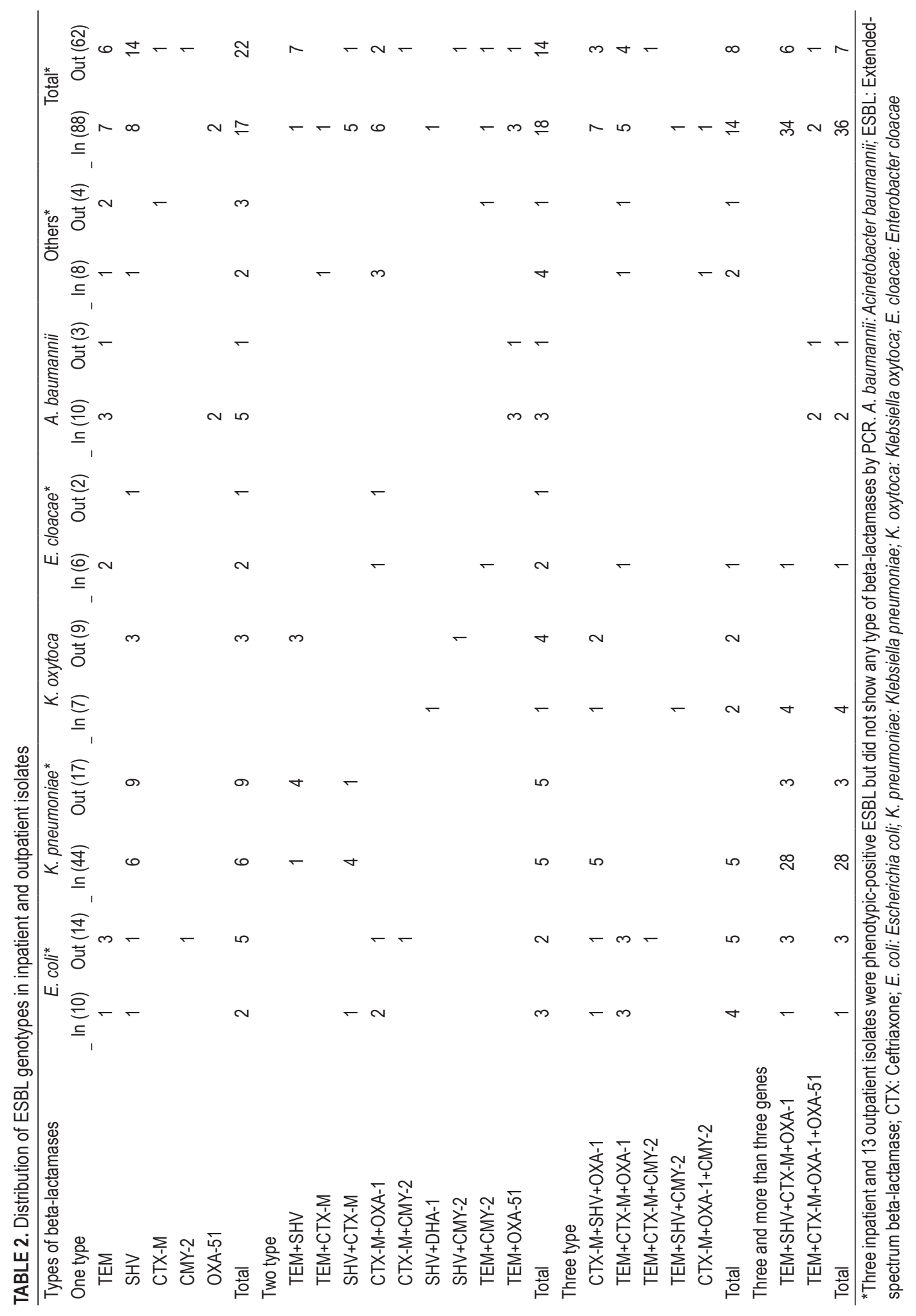




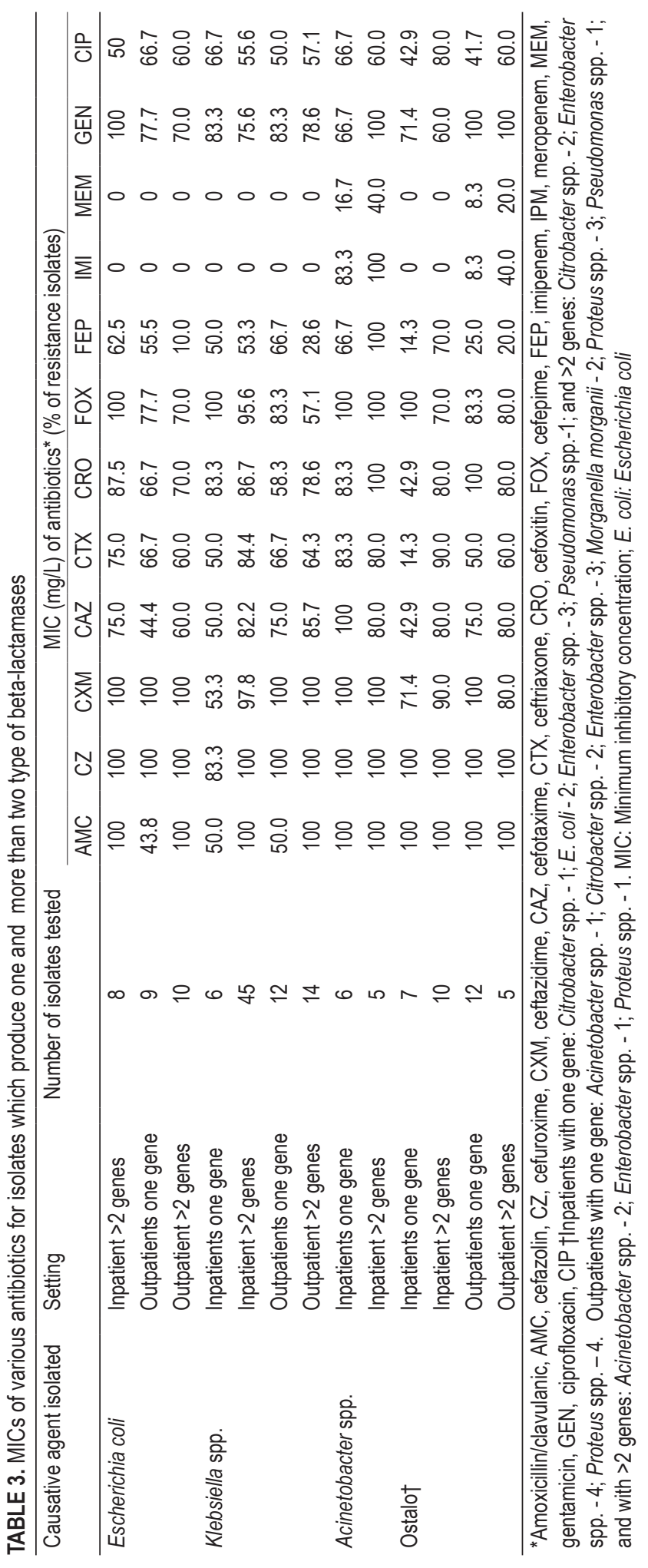




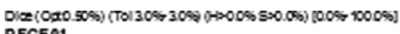
PFGE01

PFGE01

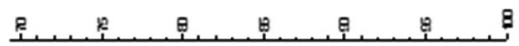
8 II

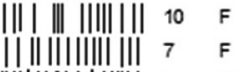
|||||||||||||||| $3 \quad M$ ||||| |||||||| ||| $12 \quad F$ |||| |||||||| ||| 18 ||||||||||||||||${ }^{2}$ |||||||||| || | $6 \quad F$ |||||||||||| क $\quad \mathrm{M}$ |||||||||| || | | $18 \quad \mathrm{M}$ |||||||||||| $18 \quad M$ ||||||| | ||||| $4 \quad M$ $\|||||||||$ s $F$ |||||||| | ||| 13 F ||||| || ||| || ||||||| 9 F |||| |||||||||||| $14 \quad$ F || |||||||| $\mid 17 \quad M$ || ||||||| || ||| $19 \quad \mathrm{M}$ || || ||| || 2 $2 \mathrm{M}$ || || ||| ||| $5 \mathrm{5}$ ||| || ||| ||| 7 M ||| || || |||| $19 \mathrm{~F}$ ||| || || |||| $20 \mathrm{~m}$ ||||||| || ||| $6 \quad F$ ||| |||||| \|\|||| |||||| $8 \quad F$ ||| || || || 3 M | |||||||| $\mid 18 \mathrm{M}$ |||||| || 18 F |||||| |||| || 2 F ||||||| || 20 F | || ||| | | 4 M | ||| ||| | $17 \quad \mathrm{~F}$ | |||| || |||||| $15 \quad \mathrm{M}$ | ||||||||||||| 13 M ||||||||| ||| $6 \quad F$ | |||||||||| $10 \mathrm{~F}$ | |||||||| $7 \quad F$ ||||||||| || $15 \quad F$ |||||||||| $17 \mathrm{M}$ | ||||||| 18 F

\section{urine $\quad<01$}

urine 74

umbilicu $<01$

urine $\quad 69$

urine 01

urine

urine

urine

wound

nmhilien

wound

wound

umbilicu

eves

urine

urine

urine

urine

urine

urine

urine

umbilicu

resp.

urine

urine

urine

urine

urine

urine

resp.

urine

urine

resp.

stome

urine

urine

stome

urine

urine

urine

umbilicu
Ward

Date Clonal of isolation group

Pediatric 24.032010. A

Ontmatient 17.03.2010. A

Ontmatient 26.052010. A

Neurology 25.02.2010. A

Pediatric 20.012010. A

Ontnationt 07.04.2010. B

Outnatiant 17.03.2010. B

Ontnatiant 27.012010. S

Ontmatiant 1203.2010. S

Pediatric 07.012010. C

Ontmztient 04.03.2010. C

Surgery 31.032010. C

Pediatric 26.03.2010. C

Outpatient 0204.2010. C

Infections 22.032010. D

Outpatient 16.03.2010. D

Pediatric 16.02.2010. D

Pediatric 06.042010. D

ICU 2202.2010. D

Neurology 19.02.2010. D

Neurology 07.04.2010. D

Pediatric 18.012010. D

Infections 11.012010. D

Pediatric 02.02.2010. E

Neurology 23.02.2010. E

Pedistric 15.03.2010. E

Interno 22.03.2010. E

Neurology 23.02.2010. F

Outpatient 31.03.2010. F

Outmationt 27.012010. F

Pediatric 22.02.2010. F

Pediatric 25.02.2010. G

Pediatric 11.012010. G

Dhusiatric 17.02.2010. H

Outoatient 06.04.2010. H

Pediatric 19.03.2010. H

Ortopedic an. 28.12.2009. H

Ortopedic an. 10.04.2010. H

Ontmatiant 24.02.2010. H

Ontmatient 17.03.2010. H

Pediatric 05.03.2010. S

FIGURE 1. Dendograms showing the genetic relatedness of the 86 Enterobacteriaceae isolates. Eight (A-H) groups of Klebsiella pneumoniae were identified by pulsed-field gel electrophoresis (PFGE) typing using the $80 \%$ similarity (a). Four clones consisted of more than five inpatient and outpatient isolates. PFGE typing was not successful in 21 isolates. Six (A-F) groups of Escherichia coli were identified by PFGE typing using the $80 \%$ similarity (b). Three clones consisted of three isolates in each of the two outpatients and one inpatient isolates. PFGE typing was not successful in 12 isolates. Four (A-D) groups of Proteus spp. were identified by PFGE typing using the $80 \%$ similarity (c). Only one consisted of three inpatient isolates. PFGE typing was not successful in one isolate. Two (A and B) groups of Enterobacter cloacae were identified by PFGE typing using the $80 \%$ similarity (d). One clone consisted of six isolates: Three inpatient and three outpatient isolates. Two ( $A$ and $B$ ) groups of Citrobacter freundii were identified by pulsed field gel electrophoresis typing using the $80 \%$ similarity (e). (a) K. pneumoniae, (b) E. coli, (c) Proteus spp., (d) E. cloacae, (e) C. freundii. ICU - Intensive care unit. 

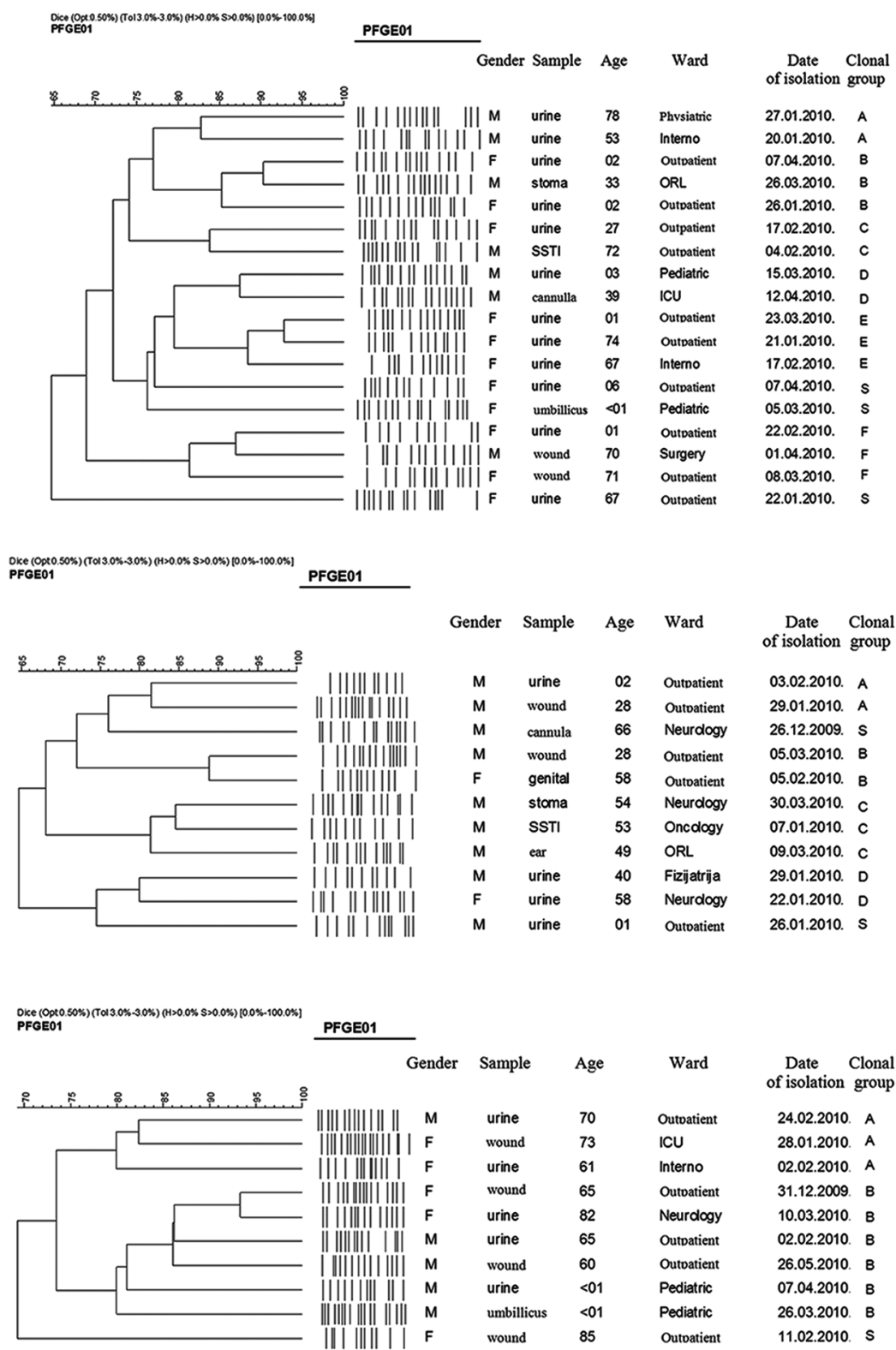

Dice (Oot $0.50 \%)(T \circ 13.0 \%-3.0 \%)(H>0.0 \% ~ S>0.0 \%)$
PFGE01 $10.0 \%-100.0 \%]$ PFGE01

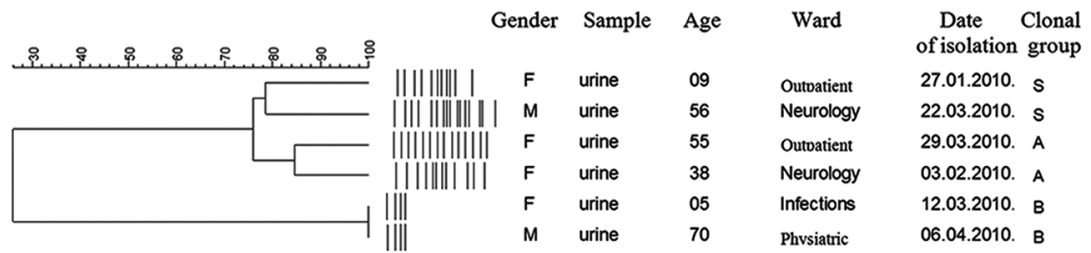

FIGURE 1. (Continued) 
with the findings in Morocco, where E. coli was the most frequently noticed (23).

Isolates obtained in this study, which produced one type of beta-lactamases, showed lower prevalence of resistance to cefotaxime, ceftriaxone, and ceftazidime than isolates coproducing more than two types of beta-lactamases.

Several distinct PFGE profiles were detected among the inpatient and outpatient ESBL- positive strains, indicating that its predominance in our setting was not due to the spreading of a single clone, but rather due to the horizontal transfer of plasmids containing genes between different species of Enterobacteriaceae. In the hospital environment, under selection pressure, plasmids could be transferred between the patients and hospital personnel by hands $(11,24)$. The possible explanation for this observation is the fact that ESBLs are encoded on plasmids and therefore could be easily transmitted as resistance gene elements for other antimicrobials, as well as from one organism to another (25).

There are many risk factors for colonization or infection with ESBL-producing isolates, such as long-term antibiotic exposure, prolonged intensive care unit stay, nursing home residency, severe illness, residence in an institution with frequent use of ceftazidime and other third-generation cephalosporin, and instrumentation or catheterization (25). Correct use of sterile gloves and systematic hand decontamination before and after visiting the patients and visitors' restriction are some of isolation measures (26).

Systematic surveillance of antimicrobial resistance which is the first step toward appropriate control of antibiotic usage does not exist in B and H. Further epidemiological surveillance studies are needed to provide useful information for prescription of antibiotics and their rational use. In addition to this, further studies are needed for a better evaluation of the epidemiology of ESBL-producing Gramnegative bacteria causing infections to develop effective prevention strategies aiming to control the spreading of infections.

\section{CONFLICT OF INTEREST}

There is no financial, personal, or academic conflict of interest.

\section{ACKNOWLEDGEMENTS}

This study was supported by a grant from the Federation Ministry of Education and Science, B and $\mathrm{H}$ (03-39-5980-58-2/08).

\section{ACKNOWLEDGMENTS}

We wish to thank Advija Hedzić, Head of the Department for Microbiology, Cantonal Hospital Zenica.

\section{REFERENCES}

1. Paterson DL, Bonomo RA. Extended-spectrum beta-lactamases: A clinica update. Clin Microbiol Rev 2005;18:657-86.

https://doi.org/10.1128/CMR.18.4.657-686.2005.

2. Woerther PL, Burdet C, Chachaty E, Andremont A. Trends in human feca carriage of extended-spectrum $\beta$-lactamases in the community: Toward the globalization of CTX-M. Clin Microbiol Rev 2013;26:744-58

https://doi.org/10.1128/CMR.00023-13

3. Tacão M, Moura A, Correia A, Henriques I. Co-resistance to different classes of antibiotics among ESBL-producers from aquatic systems. Water Res 2014;48:100-7.

https://doi.org/10.1016/j.watres.2013.09.021

4. Shahid M, Singh A, Sobia F, Rashid M, MalikA, Shukla I, et al. Bla(CTX-M), bla(TEM), and bla(SHV) in Enterobacteriaceae from north-Indian tertiary hospital: High occurrence of combination genes. Asian Pac J Trop Med 2011:4:101-5

https://doi.org/10.1016/S1995-7645(11)60046-1.

5. Bora A, Hazarika NK, Shukla SK, Prasad KN, Sarma JB, Ahmed G, et al. Prevalence of blaTEM, blaSHV and blaCTX-M genes in clinical isolates of Escherichia coli and Klebsiella pneumoniae from northeast India. Indian J Pathol Microbiol 2014;57:249-54.

https://doi.org/10.4103/0377-4929.134698.

6. Shi $H$, Sun F, Chen J, Ou Q, Feng W, Yong X, et al. Epidemiology of CTX-M-type extended-spectrum beta-lactamase (ESBL)-producing nosocomial-Escherichia coli infection in China. Ann Clin Microbiol Antimicrob 2015;14(1):4

https://doi.org/10.1186/s12941-015-0063-7.

7. Rezai MS, Salehifar E, Rafiei A, Langaee T, Rafati M, Shafahi K, et al Characterization of multidrug resistant extended-spectrum beta-lactamase-producing Escherichia coli among uropathogens of pediatrics in north of Iran. Biomed Res Int 2015;2015:309478.

https://doi.org/10.1155/2015/309478.

8. Schmiedel J, Falgenhauer L, Domann E, Bauerfeind R, PrengerBerninghoff $E$, Imirzalioglu $C$, et al. Multiresistant extended-spectrum $\beta$-lactamase-producing Enterobacteriaceae from humans, companion animals and horses in central Hesse, Germany. BMC Microbiol 2014;14:187. https://doi.org/10.1186/1471-2180-14-187.

9. El Sherif RH, Maamoun HA. Molecular characteristics of extended-spectrum betalactamases among gram-negative isolates collected in Cairo University Hospital. Comparative Clin Pathol 2013;22:733-9. https://doi.org/10.1007/s00580-012-1475-9.

10. Moland ES, Hanson ND, Black JA, Hossain A, Song W, Thomson KS et al. Prevalence of newer beta-lactamases in gram-negative clinical isolates collected in the United States from 2001 to 2002. J Clin Microbiol 2006;44(9):3318-24

https://doi.org/10.1128/JCM.00756-06. 
11. Yahya Mohsen SM, Hamzah HA, Imad Al-Deen MM, Baharudin R. Antimicrobial susceptibility of Klebsiella pneumoniae and Escherichia coli with extendedspectrum $\beta$-lactamase associated genes in Hospital Tengku Ampuan Afzan, Kuantan, Pahang. Malays J Med Sci 2016;23(2):14-20.

12. Ibrahimagić $A$, Bedenić $B$, Kamberović $F$, Uzunović $S$. High prevalence of CTX-M-15 and first report of CTX-M-3, CTX-M-22, CTX-M-28 and plasmid-mediated ampC beta-lactamase producing Enterobacteriaceae causing urinary tract infections in Bosnia and Herzegovina in hospital and community settings. J Infect Chemother 2015;21(5):363-9.

https://doi.org/10.1016/j.jiac.2015.01.003.

13. Seyedjavadi SS, Goudarzi M, Sabzehali F. Relation between blaTEM, blaSHV and blaCTX-M genes and acute urinary tract infections. J Acute Dis 2016;5(1):71-6.

https://doi.org/10.1016/j.joad.2015.07.007.

14. Clinical and Laboratory Standards Institute. Methods for Dilution Antimicrobial Susceptibility Tests for Bacteria that Grow Aerobically. $7^{\text {th }}$ ed. Approved Standard M02-A11. Wayne: CLSl; 2012.

15. Tenover FC, Emery SL, Spiegel CA, Bradford PA, Eells S, Endimiani A, et al. Identification of plasmid-mediated ampC beta-lactamases in Escherichia coli, Klebsiella spp. and Proteus species can potentially improve reporting of cephalosporin susceptibility testing results. J Clin Microbiol 2009;47(2):294-9.

https://doi.org/10.1128/JCM.01797-08.

16. Mulvey MR, Grant JM, Plewes K, Roscoe D, Boyd DA. New delhi metallo- $\beta$-lactamase in Klebsiella pneumoniae and Escherichia coli, Canada. Emerg Infect Dis 2011;17(1):103-6.

https://doi.org/10.3201/eid1701.101358.

17. Dallenne C, Da Costa A, Decré D, Favier C, Arlet G. Development of a set of multiplex PCR assays for the detection of genes encoding important beta-lactamases in Enterobacteriaceae. J Antimicrob Chemother 2010;65:490-5.

https://doi.org/10.1093/jac/dkp498.

18. Pasanen T, Jalava J, Horsma J, Salo E, Pakarinen M, Tarkka E, et al. An outbreak of CTX-M-15-producing Escherichia coli, Enterobacter cloacae, and Klebsiella in children's hospital in Finland. Scand J Infect Dis 2014:46:225-30.

https://doi.org/10.3109/00365548.2013.857045.
19. Kaufman ME. Pulsed-field gel electrophoresis. In: Woodfor N, Johnsons A, editorrs. Molecular Biology. Protocols and Clinical Applications. $1^{\text {st }}$ ed. New York, Totowa: Humana Press Inc.; 1998. p. 33-51.

https://doi.org/10.1385/0-89603-498-4:33.

20. Tenover FC, Arbeit RD, Goering RV, Mickelsen PA, Murray BE, Persing DH, et al. Interpreting chromosomal DNA restriction patterns produced by pulsed-field gel electrophoresis: Criteria for bacterial strain typing. J Clin Microbiol 1995;33(9):2233-9.

21. Wienke M, Pfeifer $Y$, Weissgerber $P$, Marschal M, Autenrieth IB, Gröbner $S$, et al. In vitro activity of tigecycline and molecular characterization of extended-spectrum beta-lactamase-producing Escherichia coli and Klebsiella pneumoniae isolates from a university hospital in south-western Germany. Chemotherapy 2012;58(3):241-8.

https://doi.org/10.1159/000339488.

22. Rakotonirina HC, Garin B, Randrianirina F, Richard V, Talarmin A, Arlet G, et al. Molecular characterization of multidrug-resistant extended-spectrum $\beta$-lactamase-producing Enterobacteriaceae isolated in Antananarivo, Madagascar. BMC Microbiol 2013;13:85.

https://doi.org/10.1186/1471-2180-13-85.

23. El bouamri MC, Arsalane L, Zerouali K, Katfy K, El kamouni Y, Zouhair S. Molecular characterization of extended spectrum $\beta$-lactamase-producing Escherichia coli in a university hospital in Morocco, North Africa. African J of Urology 2015;21:161-6.

https://doi.org/10.1016/j.afju.2015.02.005.

24. Gulamber C, Altindis M, Kalayci R, Aktepe OC. Molecular characterization of nosocomial CTX-M type $\beta$-lactamase producing Enterobacteriaceae from University Hospital in Turkey. Afr J Microbiol Res 2012;6:5552-7.

25. Ibrahim ME, Bilal NE, Magzoub MA, Hamid ME. prevalence of extended-spectrum Blactamases-producing Escherichia coli from hospitals in Khartoum State, Sudan. Oman Med J 2013;28:116-20.

https://doi.org/10.5001/omj.2013.30.

26. Rubio-Perez I, Martin-Perez E, Garcia DD, Calvo ML, Barrera EL. Extended-spectrum beta-lactamase-producing bacteria in a tertiary care hospital in Madrid: Epidemiology, risk factors and antimicrobial susceptibility patterns. Emerg Health Threats J 2012;5.

https://doi.org/10.3402/ehtj.v5i0.11589. 